\title{
New Impetus to Globalization: Development of Virtual Economic Zones
}

\author{
Dr. Karoly Nagy \\ Triones Institute of Technology \\ Budapest, Hungary \\ knagy139@gmail.com
}

\begin{abstract}
Globalization is a response of mankind to a decrease in the functions of nation states. The result of this response is the development of a global information society. Following the security measures implemented after 11 September 2011, globalization came to a halt. Although globalization is a turbulent process full of contradictions and dangerous branches, this response is crucial for the future progress of mankind and it needs a new impetus. The spread of a special form of virtual economic zones could provide globalization such impetus. The results of a research and development project concerned with the intersection of Cloud computing, Big data and the Future Internet focusing on the use of IPv6 indicate that the creation of these specific type of virtual economic zones is a feasible idea. An analysis of the social and economic impact of the zones further reveals the importance and effectiveness of the zones in the revitalization of globalization.
\end{abstract}

Keywords-globalization; information society; virtual economic zone; modularization; cloud computing; big data; cyber security

\section{INTRODUCTION}

The present paper is based on previous research carried out by the author concerning globalization and the main features of information society [1], [2]. There are still heated debates about the contents and extent of the concepts involved; however, it is beyond the scope and objective of the present paper to reflect on these often conflicting views. Instead, the author will rely on his earlier developed concept referred to in the above publications. First, a brief summary of this concept is provided and the main reasons for the slow-down of globalization are pointed out. Then the latest research results in this field are introduced, which serve as a basis for developments facilitating the revival of the process of globalization.

The author has discovered1 a new opportunity, the realization of which could give a new impetus to globalization. This innovation is made possible by Cloud Computing, Big Data applications and a switch to IpV6 internet protocol. Basically, the idea is to establish Virtual Economic Zones (regional and later global) which would provide a framework for the operation of a new generation of digital enterprises: modularized digital enterprises (MEs). The spread of these zones will

1 This research work is directed at the development of Communication Technology (ICT) Infrastructure and they take place within the framework of an FP7 ICT proposal [3]. The concept of this proposal was developed by the author of the present study. trigger fundamental social, economic and political changes all over the world. Globalization will have a new impetus. Of course not everyone will like that, but there is no other way for mankind. The other way leads to the "global institutionalization" of the $20 / 80$ ratio2

\section{A SLOW DOWN IN GLOBALIZATION}

According to Manuel Castells "the modern centralised nation-state has gradually lost its functions" [5]. The loss of functions in the modern nation-states is usually connected to globalization. Accordingly to our earlier researches [1] the globalisation is not the cause for the loss of function of nation-states, but it is rather an answer of humanity to the challenges turning up from this loss of functions. The information society is a global phenomenon, but its evolution is uneven. The basic characteristic of these uneven lurches is the centreperiphery relation. The development of the global information society is of course linked to the centre. It was in the centre that the fundamental and radical transformations began that can be linked to the evolution of the informational society.

The main aspect of the answer is the process of implementing the global informational society as a networked society. The nation states losing their functions, especially those on the semi-peripheries or the peripheries, tenaciously oppose the global transformations. These states, bent on justifying their raison d'etre, can cause considerable damage to the population of a given country. The transformation (reform) of the out-dated etatist organisational and institutional systems requires democratic conditions. The new forms of democracy are expected to appear in the information society. The age of information society will arrive when the virtual worlds created by human imagination will be reified on the basis of the achievements of electronic technology, and the participation of people in these virtual worlds becomes wide-spread, general and routine. All this will lead to a fundamental, radical and global rearrangement of social relations.

The "medium" carrying the structures of the information society is the cyberspace. The cyberspace is the rapidly widening universe of the virtual worlds. We can join the cyberspace via local virtual worlds. The cyberspace technology connects the functions of the computer with the abilities of the human

2 Such a tendency is envisioned by the following: írás [4]. 
In case we admit the above approach according to which globalization is the process of developing a global information society and we agree that the basic condition for this evolution is the personal security of the "participants" as a main priority against everything then we immediately recognise the reason for slowing down. It is nothing else but the impact of the security measures introduced following the terror acts of September 11, 2001 on the privacy rights, a security campaign lasting up to now. Certain security measures have, paradoxically, weakened the security of the people in other areas or at least caused serious potential threats [6], [7]. After all, the future of globalization depends on the successful establishment of a human centred global cyber security culture. This is facilitated by the spread of the VEZ.

\section{PRIVACY}

The necessary but often inadequate measures introduced after $9 / 11$ and governmental efforts aiming to avoid such tragedies in the future resulted in the establishment of global surveillance systems 3 , eventuating a conflict of interest between the operators of these systems and the protection of privacy rights. Obviously, the various security agencies and politicians will not easily give up access to the crystal ball provided by ICT developments, Big Data applications and data mining, through which they can observe the details of our lives. All that legal activists and soundly thinking citizens can achieve is that through stricter laws and security rules private individuals will suffer the least possible consequences of a global control4. This is already something. To the question of whether it is possible for private individuals to have a private sphere where the various authorities cannot observe them the answer is still no. Being aware of the above, however, distorts the development of individuals, social capital and social relations even if governments are trying to ensure us that the information they have obtained cannot get into the wrong hands, and those who do have access to such information are impeccable in every sense of the word [10].

The revival of globalization is in the basic interest of mankind: Challenges resulting from the diminishing functions of nation states have to be met, direct social control should be extended and exercised over political life and multinational monopolies, etc. The revival of globalization depends on radical improvements in the field of privacy. The research results of the author indicate three tendencies which will result in a change of attitude of states to privacy rights, even if it seems unchangeable at the present.

The first two tendencies are closely related to each other. The author already pointed out the fact in 1995 that besides posing an economic and national security threat, cyber security problems also present a direct threat to people's health or even lives. The latest challenge is cyber reincarnation, promoted in the "Itskov

3 Public attention was brought to certain aspect of these in connnection with the Snowden case [8]

4 The US National Strategy for Trusted Identities in Cyberspace is an excellent example of that [9] project" [11]. These challenges will inevitably put a pressure on governments to reconsider their approach to privacy. Economic interests related to the security of virtual economic zones will provide an even stronger motivation than moral considerations. These interests are based on the incredible efficiency and the resulting advantages of modularized enterprises operating within the framework of VEZ. This will bring about a general security increase, affecting the field of privacy as well.

\section{VIRTUAL ECONOMIC ZONES}

Modularized enterprises are a new generation "subspecies" of digital enterprises5. The framework for modularization and its operations is provided by socalled "Virtual Economic Zones", which implies a kind of "Service System" running mainly on the base of a virtual ICT infrastructure. The interrelation of the two concepts can be described in the following way:

The virtual economic zones provide the operating conditions required for the establishment of modularized business organizations, so called "new generation of digital enterprises" (infrastructural, Big data, Cloud, regulation etc.);

Modularized enterprises (it means modularized digital enterprises) are based on the Virtual Economic Zones (VEZ). They cannot function without the framework provided by the VEZ;

Through the development of the VEZ, the EU and other plotical-economic integrations can facilitate the creation of more effective and qualitatively new types of enterprises and organizational culture;

Operations in the VEZ's shared-parameter, modularized world will entail a profound qualitative and quantitative change in terms of businesspersons' interrelations as compared to previous deeply hierarchized business and organisational structures. In this world Trust will be of unprecedented significance. The Modularization will open up new dimensions for logistics and personal logistics, in particular. The time spent on going to work and other costs can also be decreased (especially for intellectual staff) by bringing the locations where work is actually done closer to employees by flexibly adjusting the place of activity to the locations where the persons actually involved in the task in question are staying. Presumably, this process will be supported by the speedy spread of offices and other workplaces that can flexibly be rented and adapted to the infrastructural needs, which this type of modularization can be thanked for, actually.

Besides decreasing costs of "logistics" as brought about by face-to-face communication and co-operation, the number and variety of occasions will increase, as well. As a result, mutually self-authenticating human relationships will become stronger, trust will increase and the importance of VEZ's virtual world will be reinforced. Earlier we discussed how „In cyberspace the basic precondition of the personal safety of participants and at the same time the realisation of the basic functions of virtual worlds is the evolution of direct,

5 The concept of digital enterprises is used in accodance with [12]. 
living and mutually self-authenticating human relationships between the participants. Communities of mutually authenticating participants must be formed, and networks filling up cyberspace can then be built on the mutual authentication of these communities"[13].

\section{CONCLUSION}

The renewal of globalization, which is a response of mankind to a decrease in the functions of nation states, requires the development of new cyber security solutions and the establishment of a new cyber security culture. The widespread use of the VEZ and the prevention of the loss or manipulation of the modules employed require the exclusion of covert data collection methods which present a threat to their security. Besides, in the case of the modules arguments for counterterrorist interests do not hold, either. The security solutions and security culture of the VEZ will become an integral part of economic life and the protection of privacy rights. As a result, globalization will receive a new impetus.

\section{REFERENCES}

[1] Nagy, K.: The role of knowledge centres in the evolution of the global informational society. PICMET, Volume:1, Portland, Oregon ISBN 1-890843-06-7, http://dx.doi.org/10.1109/PICMET.2001.951806

[2] Nagy, K.: Slowing down of Globalisation and the European Security. Szakmai Szemle, Scientific Board of Military Security Office. Special Issue, pp. 44-54. ISSN 1785-1181

[3] Proposal title: ICT Infrastructure for Virtual Economic Zones; Proposal number: 619693; Call: FP7-ICT- 2013-11

[4] Martin, H. P., Schumann, H.: Globalization: The 20-80 Society http://portland.indymedia.org/en/2004/02/280805.shtml downloaded: 29082013
[5] Castells, M.: The Information Age - Economy, Society and Culture. Oxford: Blackwell Publishers, 1996.

[6] G. T. Nojeim: Cybersecurity: Ideas Whose Time Has Not Come - and Shouldn't. I/S: A Journal of Law and Policy for the Information Society,Volume 8, Issue 2, pp., 408-432, 2012 http://moritzlaw.osu.edu/students/groups/is/files/2012/02/4.Noje im.pdf downloaded: 13062013

[7] Maybury , M.: Cyber Vision 2025: USAF's Plan for Cyber Advantage . CYBER Special Edition Magazine 2013, IDGAS' CYBER

http://www.oilandgascybersecurity.com/media/7926/7415.pdf downloaded: 03092013

[8] Lee, M. V.: State Department revokes NSA leaker Snowden's passport. The Associated Press, June 23, 2013 2:13 pm

[9] http://www.news1130.com/2013/06/23/ap-source-statedepartment-revokes-nsa-leaker-snowdens-passport/ downloaded: 23062013

[10] National Strategy for Trusted Identities in Cyberspace, The White House, April 2011, http://www.whitehouse.gov/sites/default/files/rss_viewer/NSTI Cstrategy_041511.pdf downloaded: 17062013

[11] Peterman, L.: Privacy's Background The Review of Politics / Volume 55 / Issue 02 / Spring 1993, pp 217-246, Copyright (C) University of Notre Dame 1993 DOI: http://dx.doi.org/10.1017/S0034670500017368 (About DOI), Published online: 05 August 2009

[12] The path to neo-humanity as the foundation of the ideology of the "Evolution 2045" party http://www.2045.com/articles/30869.htm downloaded: 1306 2013

[13] Balionyte-Merle, V. Digital Enterprise http://www.finescluster.eu/fines/jm/Publications/October-2012/Viewcategory/Page-4.html downloaded 12082013

[14] Nagy, K.: Security of virtual worlds. Tudományos és Müszaki Tájékoztatás 1996(4-5), pp. 148-154 ISSN 0041-3917 